\title{
Strategies Study on How to Achieve Good Teaching Quality for Teachers in Multi-campus Education
}

\author{
Jianchun Chen ${ }^{1}$ \\ ${ }^{1}$ Qingdao University of Science and Technology, Qingdao, China \\ Correspondence: Jianchun Chen, Qingdao University of Science and Technology, Qingdao, 266061, China. \\ E-mail: baijuan@qust.edu.cn
}

Received: May 6, 2013 Accepted: May 20, 2013 Online Published: June 1, 2013

doi:10.5539/ass.v9n7p279 URL: http://dx.doi.org/10.5539/ass.v9n7p279

\begin{abstract}
With the development of society and new epoch, more and more multi-campus universities come out. Many colleges and universities have more than one campus because of merging of universities and construction of university's new campus. And this has caused a series of problems. The problem about multi-campus has become a key research field in the development of higher education. It has a great effect on sustainable development of higher education in China. At present, people focus on the study of management question fundamental research about multi-campus. This article tries to analyze how to achieve good teaching quality as a teacher in multi-campus education according to the basic principles of education and teaching. College teacher should pay attention to the phenomenon inwardly, and try to put into practice. And college teacher should also adopt flexible and various teaching methods according to the ideological level and learning ability of students and the learning environment in different campus. Good teaching quality would be achieved in different multi-campus.
\end{abstract}

Keywords: colleges and universities, multi-campus, teaching quality

\section{Introduction}

Because of merging of the university and the construction of present campus, new campus and the branch campus, educational pattern of universities that one university has several parts in different areas, has been formed objectively. In this new situation, it breaks away from single campus system, which brings a plurality of challenges for teaching and also brings a lot of new problems for teaching. Many teachers have realized the existence of the phenomenon from thinking and have carried out practice on behavior. They have achieved good teaching effect as they take different teaching and educating methods according to the students' thinking, learning abilities and learning environment in different teaching areas. Under the operational mode of multi-campus, studies on public administration, teaching management and student thinking management have been reported. However, so far, there are few reports about how to improve the teaching quality of teaching. This paper makes a discussion on how to face multi-campus phenomenon and how to achieve better teaching effect in different teaching area from the perspectives of thing and practical behavior.

\section{Pay Attention to Multi-campus Phenomenon from Thinking}

Multi-campus is the product of China's colleges and universities, is the requirement of social development and is the inevitable product of human civilization. Colleges and universities of many countries all over the world have branches in different areas. As the economic development of our country, personnel with better knowledge and skills are required in various industries; As the development of civilization in our country, more and more civilians requires to accept higher education, because the existing colleges and universities' scale cannot meet these requirement; As the original campus is too small, multi-campus appears under this situation. Masters in universities--teachers have to teach at different campus.

After implementing multi-campus teaching, to stabilize teaching order becomes an important thing for teaching management. To improve the teaching quality is the main duty of teachers. On multi-campus phenomenon appearing, many teachers have realized that problem in thinking, but we cannot stay at the level of simply realizing this phenomenon. We should analyze phenomenon appearing in teaching. The author thinks many problems in teaching come along with multi-campus, for example, students in different campuses have different views towards the same course, so that their emphasis degree towards the same course is different; students in 
different campuses have different views towards university study, so that students at the same grade has different attitudes towards study; students in different branches have different attitude; students in different campuses have different views of outlook on life and value, so that students have different opinions towards life and society; students at the same grade have different accepting effect towards the same course, and the like.

As for merging multi-campus universities, every campus has their own original culture. Different history of every campus decides different cultural accumulation and spiritual belonging of teachers and students. At the same time, different disciplines and professional characteristics decides different thinking ways and working characters of every school. In expanding multi-campus universities, the new campuses are built from cultural desert. Some new campuses are far away from the cities, infrastructure constructions, such as transportation, entertainment, and so on, are relatively behind others. Students are often closed in their campuses and the hardware constructions are lack, so there are generally no extracurricular activities. In this kind of campuses, students may have a sense of despair like living in grasslands. Some universities arrange their lower grade students in new campus with the hope of making them study in a quiet situation to learn basic knowledge. However, the effect is not good. Because new students of university has lost, confused tempers and they often do not know what to do, isolation in geography will cause interruption or lost of campus cultural heritage. Under that situation, students are hard to enjoy their school life and even harder to get on well with the university.

We should emphasize these phenomena towards all situations of students from thinking, analyze different performance of students at the same grade, and find out reasons of problems. We cannot simply think students in one campus are good and those in another are bad. Epistemology tells us existence has its reasons. Simply think one situation is good or bad is arbitrary and it cannot disclose the original reason of the thing. As a result, we should analyze different situations in teaching and find out the source of it. Only in that way can we teach with targets and with purposes. And then we can teach students in accordance of their aptitude, in order to improve teaching effect.

Only realizing many phenomenon are inevitable products in multi-campus, performances of students are not simply right or wrong and teachers' thinking is improved, can accelerate teaching.

\section{Taking Practical Action to Cope with Various Student Performances in Different Campuses}

\subsection{Guide Students in Different Campuses with Different Educational Methods}

Students in different educational area are influenced by different culture, campus environment and social environment, which will lead to different cognitions. Those factors also cause different views towards courses and study attitudes. We should guide students in different campuses from different perspectives according to their think, and take different educational methods to help them. Taking the same educational method to the all campuses should be forbid.

\subsection{Take Different Educational Methods in Different Teaching Area}

As students in different teaching areas are influenced under different situations, which leads them have different receptivity, comprehensive ability and different senses of identity towards the same educational methods. For example, as for students in the campuses with good network construction, they have better receptivity towards teaching with online education and multimedia education. On the contrary, as for students in the campuses with bad network construction, they have worse receptivity towards teaching with online education and multimedia education. This example shows that different environments will have different influences on people with the same receptivity, so that they have different views and receptive effect towards the same thing. If we want to achieve the same teaching effect in different campuses, we should take different educational methods in different teaching areas.

Furthermore, different teaching resources in different teaching areas will lead to different homework completion situations. This calls for teachers to assign homework and discussion after class according to the situations in teaching area. In the teaching areas with large amount of books, teachers can assign homework like referring to some literatures after class. In that way, students can make full use of the book resources to obtain knowledge, and also help students to learn how to refer to literatures. If teachers ask students to write papers, it is quite possible to achieve the expected result.

In all, in order to adapt the teaching requirements of multi-campus and achieve better educational goals, teachers shall pay more attention to multi-campus phenomenon from thinking, carefully analyze them and find out the source. Teachers should take practical actions to carry our different teaching and educational methods according to students in different school cultures, environment and social environment. Try to teach students in accordance of their aptitude, in order to improve teaching effect. 


\subsection{Conclude Teaching and Educational Rules and Achievements under the Situation of Multi-campus Operation in Time}

The appearance of new things always has new external manifestation and development rules which cannot be controlled. In China, multi-campus only exist for about ten years, some universities only have braches for several years and still some are constructing new campuses. Under this kind of situation, there are new problems in teaching. As a teacher teaching in the frontline, he should have sharp insight and abilities to analyze things development rules, in order to grasp the cognition and understanding of students to the discipline and the course. Adjust the teaching method according to the feedback of students. At the same time, teachers should keep concluding all kinds of phenomenon in multi-campus, and find out the rules to better improve our teaching ability.

At the present stage, the expanding of multi-campus teaching faculties and managers are slow, compared with the number of students. Full-time teacher resource supply is seriously lack. Course duties are increased to teachers, so sometimes there is a teaching class which involves several natural classes. As for some courses, there are nearly ten natural classes sitting together for one class. Teachers have to go among different campuses or branches and most time are spent on the road. Under such high strength and heavy work, as teachers, they shall strive for self benefits more actively, so that work for self benefits while the teaching quality is guaranteed. Teachers should take part in making and discussing for university reformation on distribution system, and work for their own benefits. Managers should know hardworking of teachers and make system to regulate teachers' treatment and various welfares. Output effect of educational costs depends on the proportion of the invested full-time teachers. Teachers' dominate role in university shall be established. They should reform on the distribution system and set up scientific and systematic training and using mechanism for teaching and researching talents. Gradually improve treatment salaries for teachers in order to inspire their working enthusiasm to further improve teaching quality.

2.4 Strengthen Communication between Teachers and Students, Enhance Study Interests of Students and Improve Teaching Quality

Teachers in colleges and universities mainly live in one place and mainly at the original campus. During the development process of multi-campus, students' professional elective courses are limited and it is not convenient for teachers to work. Many teachers come before class and go immediately after class, so that teachers and students are separated. To improve teaching quality and to reduce teaching costs become a pair of conflict. Course teachers, especially elective course teachers have to go among several campuses, so unified course setting and teaching design cannot be suitable for students in different grades and majors. Targets and creativity of the course may lose. In that way, contents taught by teachers to students are some boring information lack of personal features. Teachers teach at different campuses which makes them tired so that teaching quality is seriously influenced. After single campus changed into multi-campus, attitude of teachers and students becomes complex. As for new branches, they are often at remote area, their infrastructure constructions and surrounding facilities are weak, and campus cultural constructions cannot be effective in short period. Teachers and students in new campus may feel they are not valued or are marginalized. Sense of Identity and sense of belonging are relatively weak. Teaching quality is also influenced. After class, teachers often lack time and energy to communicate with students and few teachers make full use of time to communicate with students. So teachers lack fully understanding towards students' study effect, which is also an important part during teaching process.

As the continuous construction and improvement of surrounding facilities, some teachers live in or near new campus gradually, which plays an active role in improving teaching quality in new campus. In addition, in teaching practice, managers can elect a set of young full-time teachers as head teachers of classes in different campus to increase contact chance for teachers and students. In daily life for teachers to regulate students, they can help students to learn some technical skills. At the same time, virtual consulting online with internet is also a way to deepen communication between teachers and students.

If students can contact teachers more and know more information after class, it is good for them to broaden their horizon, improve their study interests, develop their enthusiasm of life and improve better study quality.

\subsection{Teach Frontier Discipline, Stimulate Interest in Learning and Improve Teaching Quality}

As transmitters of cultural knowledge, teachers are also learners and masters of frontier knowledge. We hold frontier discipline and students are eager to learn knowledge, so their enthusiasm is easy to be inspired. We should teach frontier knowledge in right time and place according to actual situations, inspire study desire of students and improve their learning interests. At the same time, introduce research achievement and different schools of their majors and emphasize upgrading of their teaching contents. Teachers should combine old 
knowledge with new knowledge, in order to inspire students' thirst for knowledge and innovation spirit. Expert lectures in university shall be held at different branches and organize teachers and students to attend; furthermore, share academic lecture data or videos. In these ways, we can enrich students' cultural life and activate campus academic atmosphere, in order to promote academic communication and let teachers and students know frontier information and scientific results of all disciplines.

\section{Conclusion}

Colleges and universities in China adopting multi-campus education and education in different areas promote the development of education industry, but also bring some inevitable problems. How to solve those problems still needs co-hard working of all educators and managers. As a teacher, he should pay attention to multi-campus phenomenon in thinking, analyze all kinds of reflections and cognitions of students to courses, take different teaching and educating methods in practice and conclude all kinds of rules under the situation of multi-campus. Only in that way can improve teachers teaching ability as well as improve their teaching quality. They can cultivate qualified talents if they achieve better teaching effect among different teaching areas.

\section{References}

Gao, L. (2005). Problems and Experience Reference on College and University Multi-campus Management. China Higher Education Research, (12).

Lanzhou University Documents. (2006). Opinions on Improving Tutoring, Answering, Communicating and Discussing System (Trial Implementation). No. 16.

Ren, J. B., \& Tan, C. (2006). Thoughts on University's Ideological and Political Education Effective Carrier under New Situation. Jiangxi Educational Research, (3), 34.

Sui, W. H., \& Han, W. Q. (2006). Students teaching and Management Analysis under Universities with Multi-campus. Journal of Shandong Institute of Education, (3), 24.

Wang, H. (2012). Challenges and Countermeasures Faced by Teaching Secretaries in Multi-campus. The Science Education Article Collects, (9), 192.

Wu, Y. C., Luo, C., \& Ding, G. F. (2006). Problems and Countermeasures for Multi-campus Teaching Management. Journal of South China University of Technology (Social Science), (6), 78.

Wu, Y. Q., \& Xiang, Y. (2006). Thinking for Multi-campus Teaching Management Mode in Underdeveloped Area. Shanxi Education (Academic), (8), 36.

Xu, G. H. (2004). University Multi-campus Management Strategy. University Logistics Research, (5), 46.

Yang, W. B., \& Huang, W. (2005). University Multicampus Education- Comparision and Selection of University Teaching Management Mode. Jiangsu Higher Education, (4), 61.

\section{Copyrights}

Copyright for this article is retained by the author(s), with first publication rights granted to the journal.

This is an open-access article distributed under the terms and conditions of the Creative Commons Attribution license (http://creativecommons.org/licenses/by/3.0/). 